\title{
Saúde do trabalhador: uma experiência de educação em saúde vivenciada pelo PET-Saúde Independência III - Montes Claros/MG
}

Ana Cecília Versiani Duarte Pinto*, Iram Alkmim Cerqueira*, Felipe Ribeiro Néri*, Marisa Carvalho Martins**, Patrícia Helena Costa Mendes***, Ana Paula Ferreira Maciel****, Mariano Fagundes Neto*****

* Acadêmicos do PET-Saúde e do Curso de Medicina da Universidade Estadual de Montes Claros, Unimontes

** Acadêmica do PET-Saúde e do Curso de Odontologia da Universidade Estadual de Montes Claros, Unimontes

*** Preceptora do PET-Saúde da Unimontes e Cirurgiã-dentista de Família da Secretaria Municipal de Saúde de Montes Claros, Minas Gerais

**** Preceptora do PET-Saúde da Unimontes e Enfermeira de Família da Secretaria Municipal de Saúde de Montes Claros, Minas Gerais

***** Preceptor do PET-Saúde da Unimontes e Médico de Família da Secretaria Municipal de Saúde de Montes Claros, Minas Gerais

\section{RESUMO}

Atualmente, o Ministério da Saúde desenvolve políticas públicas e incentiva ações em saúde voltadas para grupos vulneráveis, dentre estes o gênero masculino e os trabalhadores. Tais grupos procuram pouco as unidades de atenção primária à saúde ficando mais predispostos a agravos de doenças possivelmente evitáveis. Nesse sentido, uma importante ferramenta utilizada na estratégia saúde da família é a educação em saúde, uma vez que a compreensão dos condicionantes do processo saúde-doença oferece subsídios para a adoção de hábitos saudáveis. O presente trabalho tem por objetivo descrever, através de um relato de experiência, uma atividade de educação em saúde, relacionada às Doenças Sexualmente Transmissíveis, voltada para um grupo de homens trabalhadores de uma empresa de construção civil. A ação foi realizada por acadêmicos e preceptores do PET-Saúde da Estratégia Saúde da Família Independência III do município de Montes Claros/MG. A atividade de educação em saúde foi avaliada satisfatoriamente tanto pelos trabalhadores, que destacaram positivamente o fato de a ação ter sido desenvolvida em ambiente de trabalho, como pelos acadêmicos, que tiveram a oportunidade de vivenciar o trabalho em equipe $\mathrm{e}$ intersetorial. Pode-se concluir que a atenção à saúde do trabalhador é uma importante estratégia para atingir a população masculina em idade produtiva, prevenindo doenças e melhorando a qualidade de vida. Além disso, iniciativas como o PET-Saúde estão em consonância com a integralidade da assistência proposta pelo SUS, através de ações multidisciplinares que buscam a efetividade da atenção primária.

\section{DESCRITORES}

Educação em saúde. Saúde do trabalhador. Atenção primária à saúde.

$\mathbf{0}$ Programa de Educação pelo Trabalho para a Saúde (PET-Saúde) é regulamentado pela Portaria Interministerial $\mathrm{n}^{\circ} 421$, de 03 de março de 2010 e tem como fios condutores a integração ensino-serviço-comunidade e a multidisciplinaridade. O PETSaúde representa uma parceria entre a Secretaria de Gestão do Trabalho e da Educação na Saúde-SGTES, Secretaria de Atenção à Saúde - SAS e Secretaria de Vigilância em Saúde - SVS, do Ministério da Saúde, a Secretaria de Educação Superior - SESu, do Ministé- 
rio da Educação e a Secretaria Nacional de Políticas sobre Drogas. Objetiva iniciar os acadêmicos no trabalho da estratégia saúde da família, desenvolvendo ações de promoção da saúde, prevenção das doenças e atendimento curativo-reabilitador. ${ }^{8}$

Dentre as ações desenvolvidas na estratégia saúde da família, a educação em saúde é um recurso por meio do qual o conhecimento científico, por intermédio dos profissionais de saúde, atinge o cotidiano das pessoas. Este recurso é importante, uma vez que a compreensão dos condicionantes do processo saúde-doença oferece subsídios para a adoção de novos hábitos e condutas de saúde. ${ }^{1}$ Assim, a educação em saúde é um processo que abrange a participação de toda a população e não apenas das pessoas sob o risco de adoecer.

Uma educação em saúde ampliada inclui políticas públicas, ambientes apropriados e reorientação dos serviços de saúde para além dos tratamentos clínicos e curativos. Assim, propõe propostas pedagógicas libertadoras, comprometidas com o desenvolvimento da solidariedade e da cidadania, orientando-se para ações cujas essências estão na melhoria da qualidade de vida e na "promoção e valorização do homem". ${ }^{9}$

Nesse contexto, o Ministério da Saúde desenvolveu políticas públicas voltadas para grupos vulneráveis, dentre estes destacam o gênero masculino e os trabalhadores. O investimento em Saúde do Homem e Saúde do Trabalhador visa qualificar a atenção primária para atender as demandas específicas destes grupos, resguardando a integralidade da assistência.

A Política Nacional de Saúde do Homem ressalta que os homens são mais vulneráveis às doenças, sobretudo às enfermidades graves e crônicas e que morrem mais precocemente que as mulheres. Além disso, eles não buscam os serviços de atenção primária, adentrando o sistema de saúde pela atenção ambulatorial e hospitalar de média e alta complexidade. As principais justificativas para a não adesão do homem ao serviço de saúde são agrupadas em barreiras sócioculturais e barreiras institucionais. ${ }^{3,7}$

As barreiras sócio-culturais são exemplificadas pelo estereótipo de gênero, segundo o qual o homem se julga invulnerável e a doença é um sinal de fragilidade, que não faz parte do universo masculino. ${ }^{3}$

Braz (2005) ${ }^{4}$ evidenciou, a partir de dados de morbimortalidade, que há um desfavorecimento significativo em termos de saúde em relação aos homens. Eles morrem mais cedo do que as mulheres e recorrem menos às consultas. Internam-se mais gravemente e procuram a emergência quando já não suportam mais a doença.
Há uma relação também com a formação da subjetividade masculina que é complexa e árdua, pois é baseada em contraposição a não ser mulher, homossexual ou criança. O homem na formação de sua personalidade é colocado em uma posição vulnerável, uma vez que ainda menino é educado a superar seus medos, ser forte e se proteger para adquirir condições futuras de patriarca. Tal vulnerabilidade nessa composição de personalidade impregna repercussões psíquicas e físicas. Assim, o sentimento cultivado de relutância excessiva de ser frágil e adoecer faz com que o homem fique mais predisposto aos agravos de doenças possivelmente evitáveis. Além disso, os serviços e as estratégias de comunicação privilegiam as ações de saúde voltadas para a criança, o adolescente, a mulher e o idoso. ${ }^{4,5}$

Laurenti $(2005)^{6}$ realizou um estudo em que observou a sobremortalidade masculina por causas externas. Dentre essas causas, o tipo de violência mais importante é o homicídio, vindo a seguir os acidentes de transporte. São também atribuídos à sobremortalidade:

- transtornos mentais e comportamentais devido ao uso de álcool e de outras substâncias psicoativas, significativamente associados ao homem,

- mortes por doenças do aparelho digestivo, com destaque para a cirrose hepática, informada ou não com associação ao alcoolismo.

O estudo sugeriu certa fragilidade do gênero masculino e a necessidade de intervenção política para amenizar a questão.

Em relação às barreiras institucionais, muitos homens apontam a condição de provedor como justificativa para não procurarem a atenção primária. Isto porque o horário do funcionamento do serviço coincide com a carga horária do trabalho e, muitas vezes, perde-se um dia inteiro em filas para marcação de consultas, sem que necessariamente tenham suas demandas resolvidas em uma única consulta. Não se pode negar que na preocupação masculina a atividade laboral tem um lugar de destaque, sobretudo em pessoas de baixa condição social, o que reforça o papel historicamente atribuído ao homem d ser responsável pelo sustento da família. ${ }^{3}$

Nessa perspectiva, a Atenção à Saúde do Trabalhador é uma importante estratégia para atingir a população masculina em idade produtiva, prevenindo doenças e melhorando a qualidade de vida.

A saúde enquanto patrimônio máximo do trabalhador é condição essencial e fundamental para o exercício de qualquer atividade e para o convívio so- 
cial. É indissociável do trabalho e é ferramenta primeira no desenvolvimento das relações de produção. ${ }^{2}$

A Política Nacional de Segurança e Saúde do Trabalhador - PNSST considera como trabalhadores todos os homens e mulheres que exercem atividades para sustento próprio e/ou de seus dependentes, qualquer que seja sua forma de inserção no mercado de trabalho, no setor formal ou informal da economia. Esta política tem como principais diretrizes a ampliação das ações, visando à inclusão de todos os trabalhadores brasileiros no sistema de promoção e proteção da saúde e a harmonização das normas e articulação das ações de promoção, proteção e reparação da saúde do trabalhador. ${ }^{2}$

Observa-se que o incentivo à saúde do trabalhador é crescente no Brasil e envolve não somente medidas governamentais, mas também ações de promoção de saúde pela atenção primária em conjunto com as empresas. Estas, atualmente, não se preocupam apenas em reduzir os riscos de acidentes ocupacionais, pois reconhecem que a saúde faz parte do ambiente em que o trabalhador se insere. Assim, atuar nos determinantes do processo saúde-doença com medidas de educação em saúde aumenta a capacidade laborativa do trabalhador, a produtividade e diminui o ônus causado pelo adoecimento, tanto para o empregado quanto para o empregador.

Baseado neste contexto, este trabalho tem por objetivo, descrever, através de um relato de experiência, uma atividade de educação em saúde voltada para homens trabalhadores de uma empresa do ramo de construção civil, desenvolvida por acadêmicos dos cursos de odontologia, medicina e enfermagem da Universidade Estadual de Montes Claros, integrantes do PET-Saúde.

\section{MATERIAIS E MÉTODOS}

O PET-Saúde na Equipe de Saúde da Família (ESF) Independência III, Montes Claros/MG, foi estruturado no ano de 2011 com um cronograma de grandes temas norteadores do trabalho ao longo dos meses. O tema selecionado para Maio, Junho, Julho e Agosto/2011 foi Saúde do Trabalhador.

A ação em saúde desenvolvida no presente trabalho constituiu-se de uma parceria dos acadêmicos do PET-Saúde e profissionais de saúde médico, enfermeira e cirurgiã-dentista da ESF - preceptores do programa - com uma empresa de construção civil, que gerencia uma obra para construção de casas populares dentro da área de abrangência da ESF.

O tema acordado entre a técnica de segurança do trabalho responsável pela obra e a equipe do PETSaúde foi Doenças Sexualmente Transmissíveis (DST's). Este tema foi escolhido por constituir um importante determinante da saúde do homem em idade produtiva, que é negligenciado pelas concepções de gênero da sociedade e pela tendência dos homens de assumir comportamentos de risco.

A empreiteira emprega cerca de 120 trabalhadores e dentre estes a maioria é residente na área de abrangência da ESF Independência III.

Foram realizadas no dia 20/06/2011, no próprio local da obra, três oficinas com duração média de trinta minutos cada, com três grupos diferentes, divididos por zona de trabalho. No total, 87 trabalhadores participaram da atividade dirigida por duas acadêmicas do curso de odontologia, uma acadêmica de enfermagem e uma acadêmica de medicina e pelos preceptores do PET-Saúde.

Foram utilizados cartazes, álbuns seriados e perguntas problematizadoras para envolver os participantes, enfocando a transmissão, os sinais e sintomas das principais DST's no homem, bem como as formas de prevenção.

As oficinas iniciaram com uma dinâmica em que os trabalhadores deveriam anotar em um papel dúvidas sobre o tema e colocá-las em uma caixa. Ao final da oficina, as dúvidas eram lidas anonimamente e, aquelas que não haviam sido contempladas durante a discussão, eram respondidas junto com os participantes.

Após a dinâmica, foram abordadas as formas de transmissão das DST's, bem como outras formas de interação pessoal que não transmitem essas doenças.

Em um terceiro momento, foram utilizados cartazes com fotos dos principais sintomas das DST's no homem e um álbum seriado. $\mathrm{O}$ material dividia as doenças em categorias:

1) doenças causadoras de feridas: herpes, sífilis, cancro mole;

2) doenças causadoras de corrimento: gonorréia, clamídia, tricomoníase;

3) verrugas: HPV e

4) HIV/AIDS.

Em cada exposição os trabalhadores eram motivados a perguntar e a responder questões sobre essas enfermidades, como por exemplo:

- qual o agente causador,

- quais as manifestações clínicas,

- qual modo de transmissão e

- quais as formas de tratamento. 
Por fim, foram distribuídos preservativos masculinos e panfletos que condensavam as principais informações da oficina e continham telefone e endereço do centro de testagem e aconselhamento de Montes Claros - Minas Gerais. Além disso, os trabalhadores foram orientados quanto ao uso correto do preservativo masculino e feminino e estimulados a comparecer à unidade de saúde caso tivessem algum sintoma ou desejassem sanar outras dúvidas.

\section{RESULTADOS E DISCUSSÃO}

Este trabalho de ação em saúde voltou-se para o fornecimento de informações acerca das DST's, suas formas de transmissão e prevenção para um grupo que procura pouco o serviço de saúde.

Como os trabalhadores possuíram um papel ativo na construção das oficinas, mesmo com a manutenção da temática e do roteiro, cada uma apresentou singularidades:

- No grupo 1, os trabalhadores eram mais expansivos, tinham muitas dúvidas e não mantiveram a discussão em uma única doença.

- O grupo 2 teve o maior número de participantes, debateram muito sobre as formas de prevenção e os comportamentos de risco em relação as DST's e apresentaram interesse particular pelas doenças que causam corrimento.

- O grupo 3 era o que continha o menor número de participantes. Nesta, houve interesse particular em relação às formas de manifestação da sífilis e da AIDS.

Alguns pontos foram comuns entre os três grupos:

- destaque às vias de transmissão e não transmissão das DSTs,

- dúvidas sobre o acometimento ocular da gonorréia,

- o significado das lesões do "cancro mole", que muitos relacionaram essa doença à impotência e

- o uso correto do preservativo.

A atividade de educação em saúde foi avaliada de forma positiva pelos trabalhadores destacando a execução da mesma no próprio ambiente de trabalho. Além disso, destacaram a metodologia problematizadora utilizada nas oficinas como uma estratégia facilitadora da aprendizagem.

Para os acadêmicos participantes do PET-Saúde essa atividade foi considerada satisfatória, pois vivenciaram, a partir de uma experiência de trabalho em equipe, o processo de integração ensino-serviço-co- munidade e a multidisciplinaridade, principais eixos norteadores do programa.

\section{CONCLUSÕES}

As ações multidisciplinares em saúde para serem efetivas requerem planejamento estratégico e incentivo desde a graduação até a atuação profissional. Desta forma, iniciativas como o PET-Saúde estão em consonância com este objetivo e com a integralidade da assistência proposta pelo SUS.

A Saúde do Homem e a Saúde do Trabalhador são exemplos de áreas de atuação em expansão e que requerem metodologias ativas de intervenção adequadas à realidade vivida por estes grupos.

A experiência com oficinas problematizadoras dentro do local de trabalho rompe com justificativas seculares de incompatibilidade da jornada com o funcionamento dos serviços de saúde e ainda reacende a importância de prevenir a doença, reconhecê-la e tratá-la.

Conclui-se assim que a promoção de saúde e a educação em saúde são princípios desejáveis para a atuação em Saúde do Trabalhador, pois engloba o conceito amplo de saúde, que prevê bem-estar físico, social e emocional e não apenas a ausência de doença.

\section{ABSTRACT}

Occupational health: a health education experience undergone by "Independência III PET-Saúde" -

\section{Montes Claros, MG}

The Ministry of Health is currently developing public policies and encouraging health-related measures targeting vulnerable groups that include males and workers. These groups rarely seek primary healthcare units, and this makes them more prone to an exacerbation of a potentially preventable disease. With this in mind, an important tool used in the Family Health Strategy is health education, since the understanding of the determinants of the health-disease process helps adopting healthy habits. This paper aims to describe a health education activity related to sexually transmitted diseases, through an experience report. It is focused on a group of male workers of a construction company. The action was taken by students and instructors of the "PET-Saúde of Independência III" Family Health Strategy Program. The activity of health education was evaluated satisfactorily both by workers, who highlighted the fact that action was taken in the workplace, and by students, who had the opportunity to experience the teamwork 
Saúde do trabalhador: uma experiência de educação em saúde vivenciada pelo PET-Saúde Independência III Montes Claros/MG • Pinto ACVD, Cerqueira IA, Néri FR, Martins MC, Mendes PHC, Maciel APF, Fagundes Neto M

and inter-area work. It can be concluded that heightening awareness to occupational health is an important strategy for reaching the male population of working age, thus preventing disease and improving quality of life. In addition, initiatives like "PET-Saúde" are consistent with the integral care offered by SUS, through multidisciplinary actions seeking primary care effectiveness.

\section{DESCRIPTORS}

Health education. Occupational health. Primary health care.

\section{REFERÊNCIAS}

1. Alves VS. Um modelo de educação em saúde para o Programa Saúde da Família: pela integralidade da atenção e reorientação do modelo assistencial. Interface-Comunic Saúde Educ. 2005; $9(16): 39-52$.

2. Brasil, Ministério do Trabalho. Política Nacional de Segurança e Saúde do Trabalhador. Brasília, 2004.

3. Brasil, Ministério da Saúde. Política Nacional de Atenção Integral a Saúde do Homem. Brasília, 2008.
4. Braz M. A construção da subjetividade masculina e seu impacto sobre a saúde do homem: reflexão bioética sobre justiça distributiva. Ciência \& Saúde Coletiva. 2005;10(1): 97-104.

5. Gomes R, Nascimento EF, Araújo FC. Por que os homens buscam menos os serviços de saúde do que as mulheres? A explicação de homens com baixa escolaridade e homens com ensino superior. Cad. Saúde Pública. 2007;23(3):565-574.

6. Laurenti R, Jorge MHPM, Gotlieb SLD. Perfil epidemiológico de morbi mortalidade masculina. Ciência \& Saúde Coletiva. 2005;10(1):35-46.

7. Lourenço RA. Lins RG. Saúde do Homem: aspectos demográficos e epidemiológicos do envelhecimento masculino. Revista do Hospital Universitário Pedro Ernesto. 2010;9(1):12-19.

8. Portal Saúde [homepage]. Brasília, DF: Ministério da Saúde [acessado em 12 jun. 2011]. [2 telas]. Disponível em: < www. saude.gov.br/sgtes/petsaude > .

9. Schall VT, Struchiner M. Educação em saúde: novas perspectivas. Cad. Saúde Pública. 1999;15(2):4-6.

Recebido em 07/07/2011 Aceito em 25/07/2011 